\title{
EL ARTE EN EL CINE Y SU USO COMO AMPLIACIÓN DEL CONOCIMIENTO DEL HECHO ARTÍSTICO
}

\author{
The Art in the Cinema and his Use like Extension of the Knowledge of the \\ Artistic Fact
}

\author{
Sonia Ríos Moyano \\ Universidad de Málaga \\ srios@uma.es \\ Reyes Escalera PÉrez \\ Universidad de Málaga \\ drescalera@uma.es
}

Fecha de recepción: 7-III-2014

Fecha de aceptación: I-IV-2014

\begin{abstract}
Resumen: El cine, el arte y la cultura se mezclan e interrelacionan constantemente. Desde el nacimiento del cine, las influencias y relaciones del arte en el mismo son constatables. Con el paso de los ańos el cine se nos presenta como una herramienta de un gran poder persuasivo y educativo, de modo que en este texto insistiremos en la importancia del séptimo arte como complemento educativo en el contexto del aprendizaje de un periodo, autor u obra. El cine se fija en el arte, hace arte en movimiento, más concretamente cuando se inspira en un periodo imaginado, de ahí que en este texto compilaremos los filmes que nos muestran las grandezas, vicios y virtudes de los artistas más controvertidos de la historia moderna, así como de aquellos otros temas afines al estudio de la Historia del Arte. De ahí que sea de gran relevancia la compilación de películas que, de alguna forma tratan la vida, la obra o un periodo histórico que pueda ser utilizando para ampliación de los contenidos y los aprendizajes.
\end{abstract}

Palabras clave: Historia del arte; cine; aprendizaje; didáctica.

Aвstract: Cinema, art and culture are constantly intermingled. From the birth of cinema, the influences and relations between art and cinema are demonstrable. With the pas- 
sing of years, cinema has come to appear as a tool of great persuasive and educational power. In this article, we will insist on the importance of cinema as an educational complement to the learning of a period, author or work. Cinema looks at art, and it makes art in movement, especially, when a movie is inspired by an imagined period. Of particular relevance is an acquaintanceship with films that show us the greatness, vices and virtues of the most controversial artists of modern history, as well as topics related to the study of Art History. This is markedly important in regards to the grouping of films that focus on life or a specific work of art or historical period, as these can serve to broaden both contents and learning.

Keywords: Art History; cinema; learning; didactics.

SUMARIO: 1. Primeras vinculaciones entre el Cine y el Arte. 2. De la investigación a la acción. Enseñar y aprender con el Cine en Historia del Arte. 2.1. De la investigación... 2.2. ... a la acción. 2.3. Fomento de estrategias para el aprendizaje significativo. 3. El filme como herramienta didáctica. Aplicación práctica. 3.1. Fragmentos de películas. 4. Compendio de películas sobre arte y artistas de la Edad Moderna. 6. Conclusiones. 7. Bibliografía.

«El cine nunca es arte. Es un trabajo de artesanía, de primer orden a veces, de segundo o tercero lo más». Luchino Visconti

\section{PRIMERAS VINCULACIONES ENTRE EL CINE Y EL ARTE}

A finales del siglo XIX y principios del xx se produce la génesis del cine. En pocas décadas se convirtió en un medio de expresión con unas características propias que, hacia mediados del siglo Xx, se convertiría en uno de los medios más destacados para el entretenimiento y diversión de las masas. Se desarrolló gracias a tres factores: el científico y su investigación de los medios y las herramientas propias de lo fílmico, el creador que visionaba la historia y debía convertirla en imagen en movimiento, y el hombre de negocios que aportaba el capital suficiente para la investigación y producción del filme. Cada uno de estos factores contribuyó a su configuración, precisando década a década su fisonomía y estética a la vez que reforzaba su poder, un poder persuasivo que fue popularizándose y ganando adeptos para gestar la gran industria, una de las mayores del momento, con un crecimiento y expansión impensable en sus comienzos. Desde sus inicios hasta ahora, la imagen cinematográfica ha evolucionado casi a la par que los gustos y modas de la sociedad de los siglos XX y XXI, inspirándose en sus sociedades, preocupaciones, gentes, mitos y leyendas. Por este motivo, estudiar las relaciones del arte y el cine a lo largo de un siglo es objeto de estudio de las aproximaciones historiográficas de distintas disciplinas humanistas. 
A lo largo de la segunda mitad del siglo Xx, el cine se ha impuesto como una de las manifestaciones visuales más complejas y completas, convirtiéndose con ello en una de las expresiones más relevantes de nuestra cultura y uno de los medios más consumidos por las sociedades modernas del mundo globalizado. Son muchos los estudios que ya desde las últimas décadas del siglo XX vinieron a destacar la importante labor que el cine representa, tanto desde la forma de expresión, ya sea a través de la imagen, música y movimiento, como a través de los mensajes y valores que transmite. ${ }^{1}$ La imagen y la palabra, el discurso, el argumento, el reflejo de una sociedad, cultura o pensamiento, se hace poesía y movimiento a través de las imágenes fílmicas. Reflejo de una época, transmisor de valores o reconstrucción del pasado, ha sido y sigue siendo una de las fuentes de inspiración propias del medio, lo cual trasladado a las innovadoras técnicas y procesos fílmicos es capaz de crear una hiperrealidad, un mundo ideal y soñado capaz de producir una auténtica catarsis en el espectador.

En tal caso cabe destacar, en el ámbito concreto que nos ocupa, la relación del cine con el arte, puesto que además de su vínculo con la historia de otras disciplinas como la fotográfica, necesaria para entender el lenguaje fílmico, la historia del cine en sí misma nos muestra múltiples historias biográficas sobre numerosos artistas de la edad moderna y contemporánea. Si miramos la historia del cine, podemos observar cómo desde los años treinta con la película de Alexander Korda, Rembrandt (1936) o el filme de Albert Lewin sobre Gauguin The Moon ans Sixpence (1943) se inaugura toda una sucesión de recreaciones fílmicas inspiradas en los artistas más populares, coincidiendo en ocasiones con épocas de revalorización o descubrimiento de artistas. Rembrandt, Miguel Ángel, El Greco o Van Gogh, Gauguin, Toulouse-Lautrec, Picasso, Pollock, Basquiat, y un largo etcétera de artistas de las edades moderna y contemporánea serán objeto de versión cinematográfica, y desde entonces hasta la actualidad, -aprovechando los tirones de las modas, los homenajes o las conmemoraciones históricas-, el cine se suma al poder mediático de algunos artistas, obras, estilos o situaciones vividas para convertir en un auténtico «rey Midas» a todo cuanto se traduce al lenguaje cinematográfico.

Además de estas traslaciones artísticas al mundo fílmico, son numerosos los préstamos y apropiaciones iconográficas de lo artístico en las cintas producidas, ya sea por colaboración directa de artistas en la producción y diseños de vestuarios, attrezzo o guión en sí, además de versiones o inspiraciones en un determinado estilo. En este sentido cabe destacar las primeras contribuciones de artistas en el desarrollo de la escenografía o discurso fílmico. Uno de los primeros ejemplos más notables fueron los que realizara Salvador Dalí en Recuerda (Spellbound) de Alfred Hitchcock en el año 1945, una de las pioneras, sólo antecedida por su colaboración directa en el cine de Luis Buñuel en las

1 AA. VV., Historia general del cine, Madrid, Cátedra, 1995, 12 vols; Benet, V. J., Un siglo en sombras. Introducción a la historia y la estética del cine, Valencia, Ediciones de La Mirada, 1999; Casetti, F., Teorías del cine, Madrid, Cátedra, 1994; Gubern, R., Historia del cine, Barcelona, Lumen, 1995; Ramírez, J.A., Medios de masas e historia del arte, Madrid, Cátedra, 1988. 
memorables cintas El perro andaluz (Un chien andalou, 1929) y La edad de Oro (L'âge d'or, 1930) en las que hay numerosas trasposiciones de imágenes artísticas interpretadas poéticamente en clave social por el destacado cineasta.

No obstante, el cine en esencia es imagen, de modo que el análisis fílmico que emplea métodos iconológicos e iconográficos no es una forma más de aproximación al hecho en sí, sino que con el paso de los años se ha convertido en nuestro país en una metodología de análisis rigurosa tras los estudios del profesor Juan Antonio Ramírez. ${ }^{2}$ Coincidiendo con la época en la que se hacen las primeras historiografías cinematográficas en nuestro país y gracias a su pionera visión de la ampliación del concepto de objeto artístico a las artes en movimiento y a las producidas para el consumo masivo y popular, en Medios de masas e historia del arte $e^{3}$ Juan Antonio Ramírez inauguraba estos estudios, con métodos disciplinares de la historia del arte, aplicados a los medios de expresión que triunfaban en la segunda mitad del siglo xx tales como el comic, el cine, el diseño y el cartel. En definitiva, nuevos lenguajes expresivos que distaban de las tradicionales áreas de estudio características de las investigaciones iconológicas: el arte antiguo, medieval y moderno. ${ }^{4}$

En este trabajo no nos detendremos en el análisis fílmico en sí mucho más de lo necesario para justificar su relevancia e interés en el contexto de la edad elegida, sino que nos centraremos en mostrar al lector toda una recopilación y selección de los filmes más destacados hasta la actualidad inspirados en la vida de un artista de la edad moderna o en algún acontecimiento relevante de su trayectoria u obra con el objetivo de utilizar la imagen fílmica para reforzar y ampliar contenidos curriculares en las materias del área de estudio seńalado. El cine se convierte, por tanto, en un material de primera mano, en una herramienta de gran relevancia que puede y debe ser empleada como material de aprendizaje en un alumnado que usa cada vez más la imagen y el movimiento para comunicarse y aprender.

\section{DE LA INVESTIGACIÓN A LA ACCIÓN. ENSEÑAR Y APRENDER CON EL CINE EN HISTORIA DEL ARTE}

\subsection{De la investigación...}

Los cambios educativos de los últimos ańos han propiciado una ampliación de la consideración epistemológica de la propia disciplina. Lejos quedan ya el libro de Checa

2 Para conocer las distintas historiografías del cine, tanto español como extranjero véase la compilación de obras de Yepes, A. L., "Bibliografía española sobre Historia del cine», en Documentación de las ciencias de la información, vol. VI. Univ. Complutense. Madrid, 1982, pp. 41-55.

3 Ramírez, J.A., Op, cit.

4 García OсноA, S., "Cine e iconología: análisis del film desde la historia del arte», Quintana, no 4, 2005, p. 153. 
Cremades, García Felguera y Morán Turina, Guía para el estudio de la Historia del Arte, en el que se utilizan expresiones como «saber científico, ciencia necesariamente interdisciplinar o ciencia artística». ${ }^{5}$ Ya en los noventa, coincidiendo con el auge de los nuevos títulos y la ampliación historiográfica de la disciplina artística, los especialistas en Historia del Arte tendían más a la consideración de la misma como disciplina humanística que como ciencia artística. El profesional de la materia elabora un discurso seleccionando y ordenando lo más exhaustivamente posible, a través de una serie de datos, fuentes o acontecimientos artísticos que, al principio de su investigación, se le presentan como una sucesión de datos inconexos, ya sean imágenes, ideas o textos. En definitiva, parte de una información que debe ser interiorizada y razonada para después poder emitir un juicio de valor con entidad considerable. Las teorías y las hipótesis son las herramientas verbales y escritas con las que cuenta el historiador del arte para elaborar su discurso, pero estas especulaciones sobre el arte nunca pueden alcanzar la categoría de científicas. Son múltiples las formas de aproximación al hecho artístico y las metodologías de análisis; desde esta perspectiva, deben quedar claras que las hipótesis o teorías (construcciones retóricas e interpretativas) elaboradas por el historiador del arte no pueden ser verificadas o refutadas nunca en sentido pooperiano. Por ello, hay que saber distinguir necesariamente entre los instrumentos operativos con los que trabaja la ciencia y los métodos de investigación que asisten a las humanidades -aunque ambas sean hermanas-, porque participan en la configuración del conocimiento complejo y multidimensional del hombre y del mundo. Lo expuesto no ha de hacernos olvidar tampoco que en la tarea del historiador del arte hay una fase previa a la elaboración del análisis especulativo de la obra de arte en la que sí han de seguirse unos criterios estrictamente científicos. El primer paso, antes de elaborar cualquier teoría o hipótesis, es recopilar y contrastar aquellos datos e información de primera mano que nos pueda acercar al hecho artístico concreto que investigamos.

Desde esta otra perspectiva, en el discurso confeccionado por los historiadores de la cultura y de la creatividad artística ninguna elaboración posterior sustituye o borra un análisis, una hipótesis, una teoría o un programa interpretativo, a menos que el punto de partida para la elaboración de dicho análisis contenga datos erróneos o carezca de alguna información relevante pero desconocida en el momento de su elaboración. Afirmamos pues que la Historia del Arte es una disciplina humanística que por su carácter de «disciplina», aplica necesariamente unos criterios científicos sobre datos objetivos (aquellos que empíricamente son verificables o refutables) para, después, formular teorías o hipótesis de forma especulativa, es decir, imposible de demostrar científicamente en sentido pooperiano ${ }^{6}$, pero que nos permiten organizar y estructurar un relato sobre

Cfr. Checa Cremades, F., García Felguera, Ma de los S. y Moránturina, M., Guía para el estudio de la Historia del Arte, Madrid, Cátedra, 1980.

6 Karl R. Pooper, en 1934, fue el primero en proponer un "criterio de falsabilidad», mediante el que se puede diferenciar claramente entre lo que es ciencia y lo que no. A partir de sus estudios, una 
los acontecimientos artísticos del pasado, un relato que no puede ser científicamente demostrado, no pudiendo darse una respuesta absoluta que agote el problema. La función más importante del historiador del arte será la de ofrecer un relato lo más verosímil posible de carácter provisional, sabiendo que, a posteriori, podrán proponerse otras explicaciones distintas y tan verosímiles como la suya (que incluso la superen en algunos de sus aspectos). Con el paso del tiempo se amplía así el conocimiento creándose una estela de interpretaciones o una pluralidad de relatos inagotables no sólo por la propia naturaleza de la obra de arte en sí, sino también porque, según se suceden las distintas épocas y mentalidades, los enfoques y los intereses con los que se mira una determinada obra, artista o tendencia van cambiando ampliándose las lecturas.

Este giro reflexivo de la historia del arte, aunque parezca que devalúa su tarea, en realidad ha abierto más luz a las posibilidades que posee desde su propia condición como disciplina aplicada a la interpretación y comprensión de los fenómenos artísticos, máxime cuando en las últimas décadas el hecho artístico en sí, el objeto de estudio de la disciplina ha ampliado sus horizontes hacia las nuevas formas de expresión de la cultura actual. De este modo el estatuto epistemológico y semántico de las proposiciones sobre los significados y valores formales, sobre la intención y los méritos o deficiencias de una obra artística, instalación, diseño o filme, deviene perfectamente legítimo, traduciéndose los resultados de dichas propuestas interpretativas en investigaciones que se basan en las extendidas formas de interpretación del hecho artístico.

\section{2. ...A LA ACCIÓN}

Una vez que hemos definido y aclarado las particularidades de la investigación en la disciplina humanística que nos ocupa, nos detendremos en profundizar en el conocimiento práctico de ésta, insistiendo en las particularidades del aprendizaje del arte, sus características y las situaciones en las que se produce ese aprendizaje significativo en el alumno, de modo que conociendo esos activadores del aprendizaje humano y las distintas técnicas que nos ayudan a potenciarlo estableceremos un tándem significativo entre los métodos de aproximación al lenguaje fílmico y el uso de una película de temática artística como complemento para la aprehensión de los contenidos histórico-artísticos de un tema en cuestión.

El aprendizaje en sí es un proceso de naturaleza compleja, que se caracteriza por la adquisición de un nuevo conocimiento, habilidad o capacidad. Es preciso aclarar que, para que tal proceso se considere aprendizaje, debe ir más allá de una retención pasajera a

teoría sólo puede ser considerada como «científica» cuando puede ser refutada empíricamente. En todo caso, en humanidades no podemos seguir estrictamente a Popper, puesto que la aplicación práctica de ambas disciplinas son completamente distintas, puesto que en humanidades no podemos demostrar hipótesis ni ideas mediante el experimento y aplicación predictiva.Cfr. Pooper, K. R, Lógica de la Investigación cientifica. Madrid, Tecnos, 1980. 
corto plazo, por lo que debe ser susceptible de manifestarse en un futuro y, además, debe contribuir a conseguir soluciones ante situaciones concretas, que pueden ser incluso diferentes en su esencia a las que motivaron inicialmente el desarrollo del conocimiento, capacidad o habilidad.

En el informe sobre educación presentado a la UNESCO en 1996 y coordinado por Jacques Delors, en la segunda parte, capítulo cuatro, se indica que los cuatro pilares en los que se basa la educación son: Aprender a conocer, Aprender a hacer, Aprender a vivir juntos y Aprender a ser ${ }^{7}$. Debemos tener en cuenta que el concepto de aprender implica tanto el de asimilar como de reconstruir conocimientos, además de adquirir y usar destrezas y desarrollar actitudes. Por ello, al plantear el conocimiento de un periodo artístico nos centramos en cada uno de estos ámbitos: cognitivo, motriz y emocional, ya que el aprendizaje provoca cambios que implican la adquisición de conocimientos, de habilidades y actitudes ${ }^{8}$. Las formas del aprendizaje son comunes a todos los humanos. Los diferentes tipos de aprendizaje se van repitiendo a lo largo de nuestra vida. El aprendizaje más elemental consiste en constituir un vínculo entre un estímulo y una respuesta, pero otros tipos más complejos se basan en la imitación y el descubrimiento de manera autónoma, siendo este último uno de los más productivos a largo plazo porque implica el desarrollo de habilidades y la capacidad de resolución de problemas que implican el análisis y la emisión de juicios de valor.

En este sentido, un modelo habitual de aprendizaje es el que se apoya en los conocimientos ya adquiridos para establecer relaciones y así poder avanzar en los nuevos contenidos. Al adquirir una información nueva, el discente la relaciona con los conocimientos que ya posee. Esa nueva información se integra y adapta a su estructura de conocimiento; cuando esto se produce hablamos de aprendizaje significativo, porque lo que se asimila es coherente con el conjunto de conocimientos que ya posee el individuo. Por último, destacamos el aprendizaje por transferencia, es decir aquel que se manifiesta cuando los conceptos y destrezas adquiridos en una materia pueden trascender y aplicarse a una nueva situación o a un nuevo aprendizaje. En tal caso, estamos relacionando o transfiriendo lo asimilado y extendiendo nuestro aprendizaje conceptual.

DeLORS, J. (coord.) La educación encierra un tesoro. Informe a la UNESCO de la Comisión Internacional para la Educación del siglo XXI. París, Ediciones UNESCO, Santillana, 1996, p. 34. <http:// www.unesco.org/education/pdf/DELORS_S.PDF> (Consultado: 26.02.2014).

8 Zabalza, M.A., La enseñanza universitaria. El escenario y sus protagonistas, Madrid, Narcea Eds. 2002; López Noguero, F., Metodología participativa en la enseñanza universitaria. Madrid, Narcea, 2005; Benito, A. y Cruz, A., Nuevas claves para la docencia universitaria en el espacio europeo de educación superior. Madrid, Narcea, 2005. 


\subsection{Fomento de ESTRATEgIas PARA El APRENDIZAJE SigNificativo}

Aceptar esta frase supone vertebrar todo un trabajo para que el discente adquiera un aprendizaje autónomo, - enseñarles a aprender-, cuyo objetivo principal no es sólo que adquieran los contenidos de una materia concreta sino, además, que alcancen una serie de competencias que puedan serles de utilidad durante toda su vida lo que, en la práctica y el tiempo, supone que el individuo obtenga las estrategias necesarias para saber cómo adquirir un nuevo aprendizaje?.

El discente debe experimentar que tiene la necesidad de formarse en un tema, aprendiendo incluso a darse cuenta de sus necesidades y plantearse unos objetivos a conseguir.

El discente debe aprender a recoger la información adecuada en torno al tema, saber dónde, qué consultar y aprender a seleccionar la información que encuentra. Conocer cómo acceder a la información, seleccionarla y sintetizarla.

El discente debe aprender a sistematizar, organizar y clasificar la información obtenida.

El discente debe aprender a analizar criticamente la información que previamente ha seleccionado. Aprender a analizar supone un gran esfuerzo, sin embargo, el análisis es un proceso muy relevante en el aprendizaje porque implica un juicio valorativo y subjetivo sobre algo.

El discente debe aprender a aplicar los conocimientos adquiridos durante la fase teórica. Con la práctica se pueden aplicar los contenidos teóricos, más si lo unimos al aprendizaje del análisis crítico, lo que implica un proceso relevante que se caracteriza por la emisión de un juicio de valor ${ }^{10}$.

Si tenemos en cuenta estos aspectos, el análisis fílmico como recurso de formación complementaria en el aprendizaje está justificado ya que permite profundizar sobre temas concretos que se vinculan a las distintas materias objeto de estudio. La necesidad de aprender a analizar críticamente la información recibida, independientemente del canal de aprendizaje -oído, lectura o visión-, cobra más fuerza cuando empleamos el poder persuasivo de la imagen fílmica, la más completa, puesto que agudiza los sentidos y activa nuestra atención, la cual apoyada en los conocimientos adquiridos fomenta el juicio crítico.

$9 \quad$ AA. VV., Actividades para la enseñanza y el aprendizaje de competencias genéricas en el marco del Espacio de Educación Europeo Superior. Zaragoza, Prensas Universitarias, 2005; GIL, J. et al., La enseñanza universitaria, planificación y desarrollo de la docencia. Madrid, EOS, 2004.

10 Fernández de Haro, E., «Las tareas del profesor universitario en el EEES». Conferencia V Curso de formación para el profesor universitario novel. Facultad de Ciencias de la Educación de la Universidad de Málaga, 2007. 


\section{EL FILME COMO HERRAMIENTA DIDÁCTICA. APLICACIÓN PRÁCTICA ${ }^{11}$}

Los estudios fílmicos son una realidad en las Universidades españolas desde hace varias décadas. Sin embargo, con el paso de los años y la persecución de los objetivos del informe Delors, cada vez son más las herramientas audiovisuales que se emplean como complemento para la adquisición de conocimientos y ampliación de contenidos. Independientemente de los estudios fílmicos que se realizan en los títulos de Historia del Arte sobre su propio lenguaje y su historia ${ }^{12}$, ensayamos una propuesta de utilización del cine como complemento didáctico para favorecer el aprendizaje en la materia Iconografía e iconología.

En ella se introduce al discente en el método iconográfico e iconológico y sus fundamentos, haciendo un recorrido en bloques temáticos en los que se profundiza en los tipos iconográficos más relevantes del Renacimiento y del Barroco y su proyección en el mundo actual ${ }^{13}$.

El cine es uno de los recursos que empleamos para completar lo aprendido en las clases magistrales junto a lecturas y exposiciones del alumnado. Dicho empleo presenta dos facetas:

a: Visionado de fragmentos de películas que han sido seleccionados por la docente $e^{14}$.

b: Cinefórum como actividad formativa.

\subsection{Fragmentos de películas}

En relación con la pintura de Vanitas, que forma parte del bloque temático dedicado a la muerte y sus símbolos, se visiona un fragmento de la película Todas las mañanas

${ }_{11}$ En este epígrafe proponemos el uso del cinefórum en la materia concreta de Iconografía e Iconología, del Grado de Historia del Arte de la Universidad de Málaga al amparo del proyecto de innovación educativa titulado "Adecuación de contenidos y actividades formativas para la adquisición de competencias en asignaturas del área de Historia del Arte. Realización de un catálogo de actividades que fomenten la adquisición de competencias y su evaluación» (PIE13-145. Coord. por Sonia Ríos Moyano). Dicha asignatura es optativa y se imparte en cuarto curso. Coordinadora: Reyes Escalera.

12 García Gómez, F., «La docencia de Historia del cine desde el punto de vista de un historiador del arte», Revista Latente, no 6, 2008, (Ejemplar dedicado a las Jornadas sobre fotografía, cine e historia del arte) pp. 67-72.

13 Los discentes matriculados en esta asignatura han cursado otra obligatoria de primer curso titulada Lenguajes artísticos y lecturas de la imagen en la que han estudiado fuentes iconográficas, mitología clásica e iconografía cristiana.

14 Carracedo Manzaneda, C., "Diez ideas para aplicar el cine en el aula», en I Congreso de Español como Lengua Extranjera en Asia-Pacifico, pp. 229-267. <http://cvc.cervantes.es/ensenanza/ biblioteca_ele/publicaciones_centros/pdf/manila_2009/16_aplicaciones_03.pdf> (Consultado: 20/2/2014). 


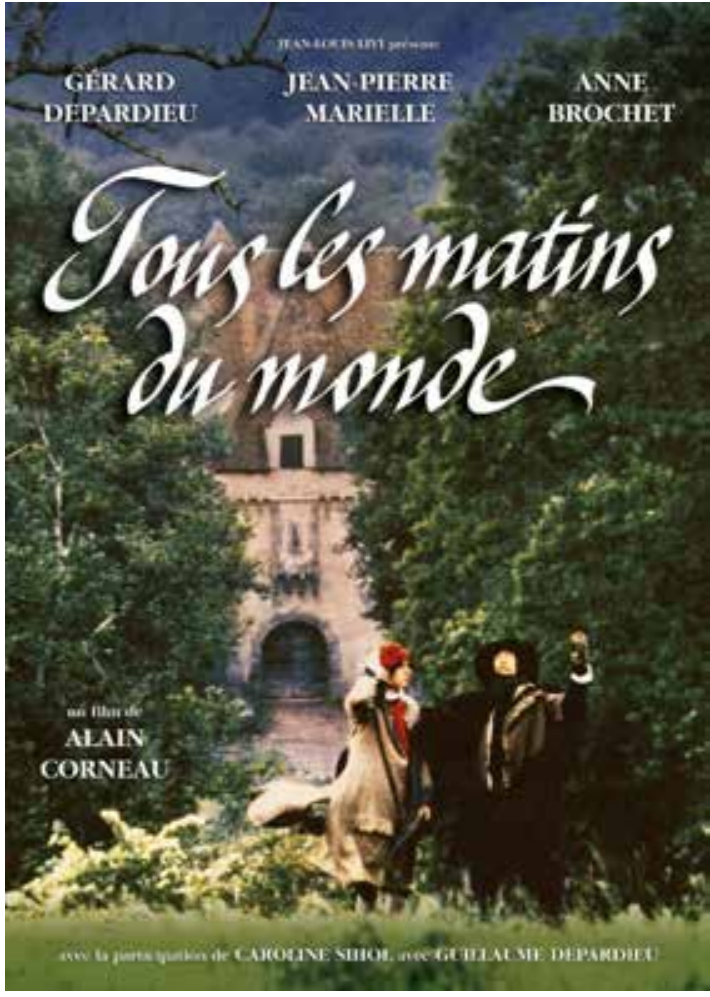

Fig. 1. Todas las mañanas del mundo (1991). Director: Alain Corneau. Intérpretes: Gérard Depardieu, Jean-Pierre Marielle, Anne Brochet, Caroline Sihol, Guillaume Depardieu, Michel Bouquet, Carol Richert.

del mundo (Tous les matins du monde, Alain Corneau, 1991) ${ }^{15}$ [Fig. 1]. El filme narra la relación entre dos destacados compositores y violagambistas del siglo XVII: Monsieur de Saint-Colombe y Marin Marais y las ideas sobre la música que tienen ambos. Maestro y alumno visitan a Lubin Baugin ${ }^{16}$ que está pintando una naturaleza muerta; la cámara se recrea en los objetos que tiene el artista ante sus ojos y que el joven Marais mira con detenimiento: tablero de ajedrez, piezas de fruta (granadas), una pluma, libros, objetos de cristal, vaso, flores, vino, pan, naipes, conchas marinas, instrumentos musicales y reloj

15 Todas las mañanas del mundo. Título original: Tous les matins du monde. Año: 1991. Duración. 115 minutos. País: Francia. Director: Alain Corneau. Intérpretes: Gérard Depardieu, Jean-Pierre Marielle, Anne Brochet, Caroline Sihol, Guillaume Depardieu, Michel Bouquet, Carol Richert. <http://www.filmaffinity.com/es/film453982.html>; <http://www.filomusica.com/filo9/matins. html>; <http://www.cineypsicologia.com/2013/09/todas-las-mananas-del-mundo-alain.html> (Consultado: 27.02.2014).

16 Pintor barroco francés que se especializó en sus primeros años en naturalezas muertas. En el filme, Marais lo conocía porque tiempo atrás le había encargado una pintura para que inmortalizara los objetos que había sobre su mesa en el momento en que se le apareció su difunta esposa. Este lienzo, que recrea la película, se titula: «Naturaleza muerta con obleas» o «El postre de las obleas» y se encuentra depositado en el Museo del Louvre (obra fechada en el segundo cuarto del siglo XVII). 

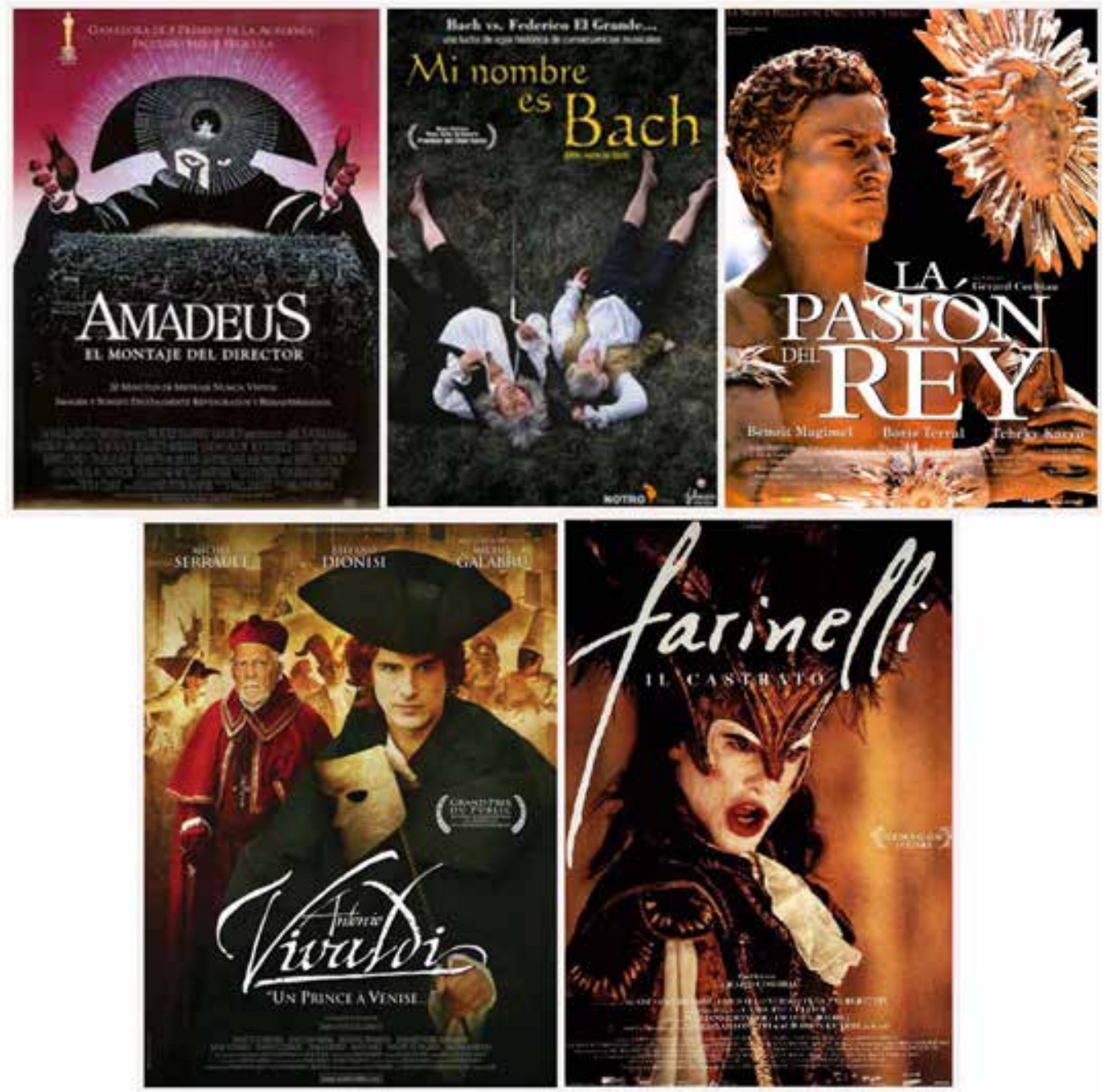

Fig. 2. Amadeus (1984), Mi nombre es Bach (2003), La Pasión del Rey (2000), Vivaldi, principe de Venecia (2006) y Farinelli il castrato (1994).

de arena ${ }^{17}$. Saint-Colombe hace una reflexión a su joven compañero: «Todo aquello que la muerte se llevará ya está en la nada. Son los placeres del mundo que nos dicen adiós al retirarse». Por tanto, esos objetos que, supuestamente, está pintado Baugin sólo para ganar dinero - «me gusta el oro, las cosas muertas dan dinero»— cobran nueva vida al

17 Estos objetos están descritos con minuciosidad en la novela en la que está basada la película La vie mode d'emploi de Georges Perec. Una de las composiciones de la película se inspira en la obra «Los cinco sentidos" (Museo del Louvre). 
convertirse en elementos propios de las Vanitas, en las que se representan elementos que simbolizan la brevedad de la vida, la futilidad de las riquezas y la nimiedad del conocimiento frente a la muerte, que es finalmente la que triunfa ${ }^{18}$.

Un nuevo bloque temático versa sobre la Literatura emblemática y su influencia en el arte. Una de las obras que se consideran antecedentes de este género es la novela de Francesco Colonna El Sueño de Polifilo, editada en 1499 por Aldo Manuzio ${ }^{19}$ y considerada por la crítica como uno de los más bellos ejemplares de la época, opinión que completa Sven Dahl cuando escribe: «es el más perfecto que haya salido de una imprenta ${ }^{20}$. En los primeros minutos de la película La Novena Puerta (The Ninght Gate, Roman Polanski,1999 ${ }^{21}$, basada en la novela de Arturo Pérez Reverte La Tabla de Flandes, el bibliófilo Dean Corso visita una biblioteca y tasa algunos de sus ejemplares más valiosos. Uno de ellos es Hypterotomachia di Polifilo, citando la edición de 1545. Con este visionado se intenta despertar la curiosidad del alumnado, ofreciéndole un ejemplo de cómo una obra, casi desconocida, es del interés del escritor, Pérez Reverte, y del realizador de la película, Roman Polanski, que la ha escogido entre otras muchas citadas por el anterior.

\subsection{Actividad formativa. Cinefórum}

Esta actividad de aprendizaje se realiza en función de las competencias que se adquieren en esta asignatura. La fiesta barroca y su iconografía es una de las materias impartidas en la misma. En esta se introduce al discente en los diferentes aspectos de la celebración barroca -tanto fiestas civiles como religiosas- en toda su complejidad, lo que obliga a abordarla desde un análisis interdisciplinar, interrogando al conjunto de saberes que la integran: ritos, códigos artísticos, juego político institucional, formas de gobierno y esquemas retóricos y literarios. En esos días la ciudad se trasformaba con decoraciones fingidas que simulaban lo viejo y arquitecturas efímeras cuyos programas exponían un mensaje didáctico y propagandístico del poder establecido.

Muchos eran los elementos que se utilizaban para que las celebraciones lucieran con todo su esplendor: decorados ficticios, cortejos y mascaradas, toros, juegos de cańas, fuegos artificiales, luminarias, luchas simuladas o naumaquias. Todos los sentidos se deleitaban, por lo que no faltaban la comida y la bebida -fuentes que manan vino, dulces

18 Cfr. Valdivieso, E., Vanidades y desengaños en la pintura española del siglo de Oro, Madrid, Fundación de Apoyo a la Ha del Arte Hispánico, 2002 y Vives-Ferrándiz Sánchez, L., Vanitas. Retórica visual de la mirada, Madrid, Encuentro, 2011.

19 Colonna, F., Sueño de Polifilo. Ed. de Pilar Pedraza. Murcia, Librería Yerba, Colegio de Aparejadores y Arquitectos Técnicos y Consejería de Cultura, 1981.

20 DAhl, S., Historia del libro, Madrid, Alianza, 1972.

21 La Novena Puerta. Título original: The Ninth Gate. Año: 1999. País: Francia, España, USA. Duración: 135 minutos. Director: Roman Polanski. Intérpretes: Johnny Depp, Lena Olin, Frank Langella, Emmanuelle Seigner, James Russo, Allen Garfield, Barbara Jefford, José López Rodero. <http://www.filmaffinity.com/es/film555281.html> (Consultado: 27/2/2014). 


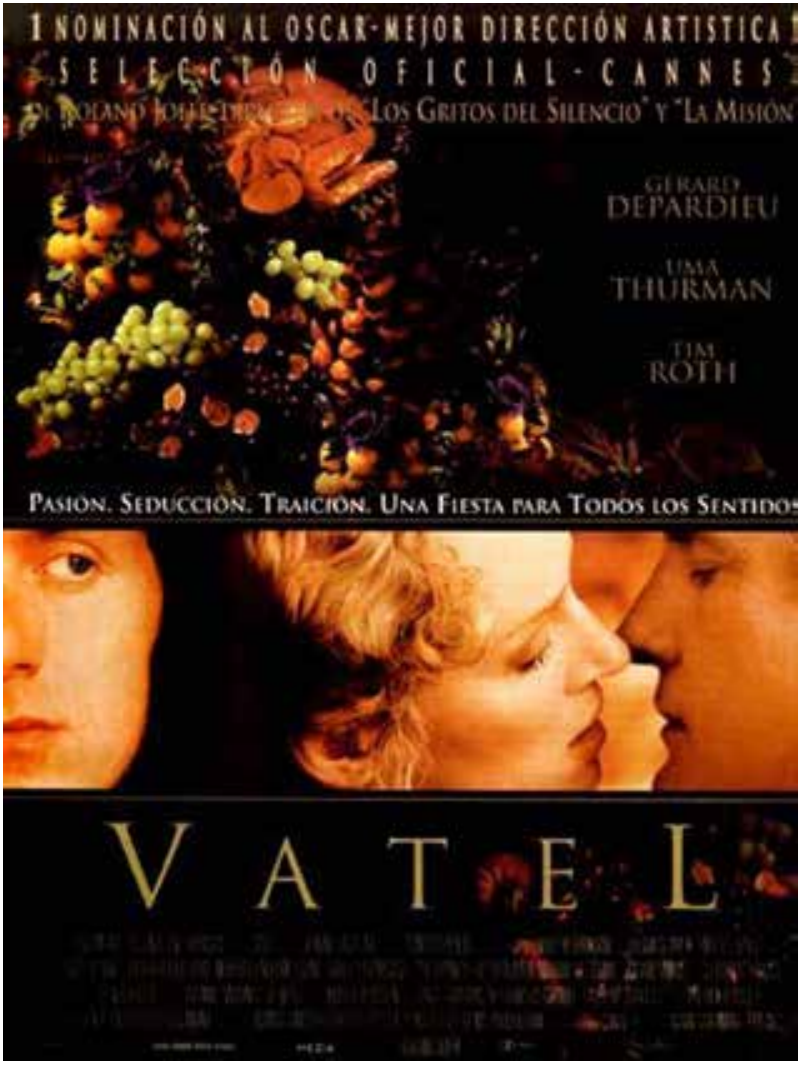

Fig. 3. Vatel. Director: Roland Joffé. Intérpretes: Gérard Depardieu, Uma Thurman, Tim Roth, Timothy Spall, Julian Glorver, Julian Sands, Murray Lachlan Young.

que se arrojan desde las ventanas de nobles y caballeros o viandas que se entregan a los pobres-. Tampoco faltaban las representaciones teatrales y la música. Esta faceta quizá sea la que más se ha valorizado en el cine, habiéndose realizado numerosos filmes en los que músicos y compositores de los siglos XVII y XVII cobran un gran protagonismo: Amadeus (Milos Forman, 1984) 22, Mi nombre es Bach (My Name is Bach, Dominique de Rivaz, 2003), La Pasión del Rey (Le roi danse, Gérard Corbiau, 2000) ${ }^{23}$ o Vivaldi, príncipe de Venecia (Antonio Vivaldi, un prince à Venise, Jean-Louis Guillermou, 2006) ${ }^{24}$; también son protagonistas conocidos intérpretes como Carlo Broschi en Farinelli il castrato (Farinelli, Gérard Corbiau1994) ${ }^{25}$. [Fig. 2]

$22<$ http://www.blogdecine.com/criticas/criticas-a-la-carta-amadeus-de-milos-forman>; $\quad<$ http:// filasiete.com/making-of/amadeus-1984-milos-forman/> <http://filasiete.com/making-of/amadeus-1984-milos-forman-3/>; <http://postersycine.blogspot.com.es/2013/04/criticaamadeus-1984-de-milos-forma.html> (Consultado: 27/2/2014).

23 Esta película narra la relación entre Luis XIV y Jean-Baptiste Lully. <http://www.cineclubsabadell. org/recursos/recursos/doc21.pdf> (Consultado: 27/2/2014).

24 <http://www.musicaantigua.com/pelicula-vivaldi-un-principe-en-venecia/>; $\quad<$ http://www.taller54.com/vpelicula.htm> (Consultado: 27/2/2014).

25 <http://www.ecured.cu/index.php/Farinelli_il_castrato> (Consultado: 27/2/2014). 
No obstante, una película que aúna los elementos más característicos de la fiesta cortesana es Vatel ${ }^{26}$, [Fig. 3] dirigida en el año 2000 por Roland Joffé2 ${ }^{27}$ y protagonizada por Gérard Depardieu. François Vatel comenzó su azarosa vida como cocinero y maestro de ceremonias de Nicolás Fouquet, superintendente de hacienda de Luis XIV. Fouquet llamó para la construcción de su palacio en Vaux le Vicomte a los mejores artistas del momento: el arquitecto Louis Le Vau, el pintor Charles le Brun y el jardinero André Le Nôtre. Para su inauguración, el 17 de agosto de 1661, invitó al rey que asistió acompañado de la reina madre Ana de Austria, el duque de Orleáns, su esposa Henriette de Inglaterra y toda la corte. Para agasajar a sus invitados Fouquet organizó una velada en la que ofreció un suntuoso banquete servido en vajilla de oro y plata en la que se pudieron degustar ochenta platos de las más variadas viandas; tras la comida los festejos tuvieron lugar en el jardín, magníficamente iluminado, en el que los invitados se solazaron con conciertos, representaciones teatrales, un ballet y fuegos artificiales. Pocas semanas después el rey, influido por Colbert, depuso a Fouquet, acusado de malversación quien moriría en la prisión de Pignerol algunos años después. Vatel huyó a Inglaterra por miedo a ser detenido y poco después fue contratado por Luis II de Borbón-Condé para que trabajara en su château de Chantilly, donde volvemos a encontrar a Le Nôtre como diseñador de los jardines.

En este contexto se desarrolla la película: es el año 1671 y el príncipe Condé, caído en desgracia, desea congraciarse con el Rey Sol invitándole a una fiesta que duró tres días. Vate ${ }^{28}$ se desvive para que todo esté del agrado de los ilustres invitados -más de tres mil-, pero esa misma perfección será su ruina, ya que terminará suicidándose por temor a perder su «honor y reputación» tras sentirse humillado porque en la cena habían faltado algunos asados - aunque no en las mesas de los más cercanos al Rey Soly terriblemente angustiado al comprobar, de madrugada, que sólo habían llegado a su cocina dos cargas de pescado, cantidad ínfima en relación con las que necesitaba para la comida del siguiente día ${ }^{29}$. Esta es la versión más conocida, aunque parece que era otro

26 Vatel. Año: 2000. País: Reino Unido, Francia. Duración: 116 minutos. Director: Roland Joffé. Intérpretes: Gérard Depardieu, Uma Thurman, Tim Roth, Timothy Spall, Julian Glorver, Julian Sands, Murray Lachlan Young. <http://www.filmaffinity.com/es/film455439.html> (Consultado: 27/2/2014).

27 <http://suite101.net/article/vatel-una-pelicula-de-roland-joffe-a17722>; <http://www.cinestrenos.com/cartelera/critica/vatel/vatel.htm>; <http://www.elinconformistadigital.com/modules.php?file=article\&name=News\&op=modload\&sid=1824> (Consultado: 27/2/2014).

28 Para más información sobre este personaje, puede consultarse Hansmann, W, Jardines del Renacimiento y el Barroco. Madrid, Nerea, 1989; Tompson, I., Los jardines del Rey Sol, Barcelona, Belacqva, 2006; Calero Ruiz, C., "Vatel y otros arquitectos de sueños efímeros. Banquetes, sentidos y triunfi en las cortes europeas de la época moderna». Revista Latente, no 9, 2011, pp. 45-58. En este último se analiza la película.

29 Los detalles de todo lo ocurrido fueron descritos por Mme. de Sévigné a su hija Françoise-Marguerite en sendas cartas firmadas los días 24 y 26 de abril de 1671. SÉvigné, Madame de, Cartas escogidas de madame de Sévigné. Buenos Aires, «El Ateneo», 1944, pp. 105-108. 
emotivo mucho más profundo el que le arrastró al suicidio: el de proclamar su libertad ante los deseos del rey ${ }^{30}$.

Esta actividad formativa se realiza en cada uno de los grupos reducidos - aproximadamente 25 discentes-. Se estructura en dos fases (ver esquema adjunto): previsionado, en los que los discentes - tres o cuatro- tendrán que investigar diferentes aspectos de la película relacionados con la materia, y postvisionado, en la que, tras el visionado del filme por parte de todos los compañeros, los discentes responsables de la actividad expondrán en clase sus conclusiones. La profesora coordina todas estas actividades y fomenta

el debate.

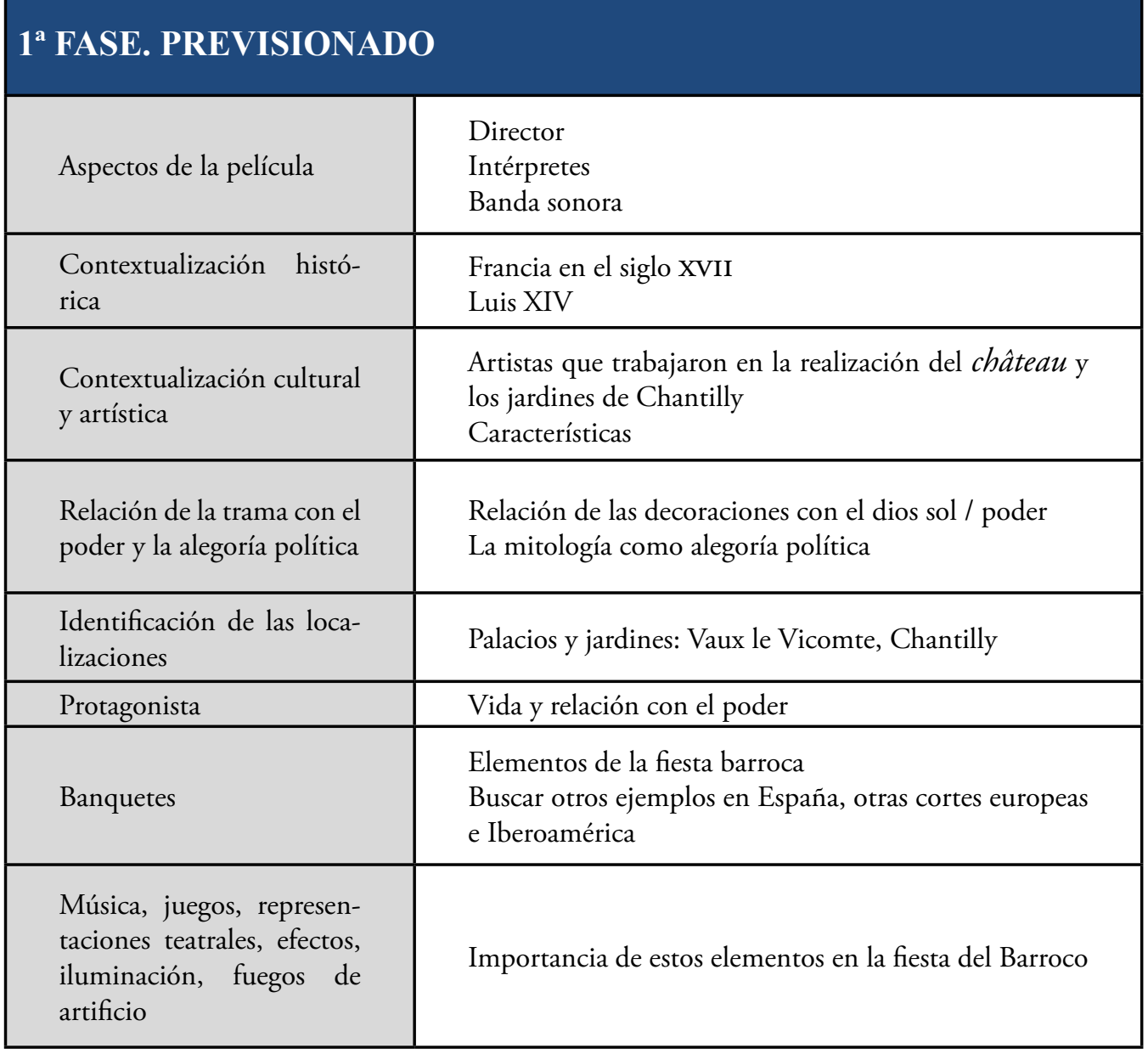

30 Luis XIV y el príncipe Condé se jugaron a las cartas a Vatel; Condé perdió y el maestro de ceremonias debía trasladarse a vivir en Versalles. 


\begin{tabular}{|l|l|}
\hline $\begin{array}{l}\text { Escenografías y decora- } \\
\text { ciones }\end{array}$ & $\begin{array}{l}\text { Características de las mismas } \\
\text { Relación con otras escenografías conocidas (grabados } \\
\text { y dibujos) }\end{array}$ \\
\hline
\end{tabular}

\section{$2^{\mathrm{a}}$ FASE. POSTVISIONADO}

\begin{tabular}{|l|l|}
\hline $\begin{array}{l}\text { Exposiciones y puesta en } \\
\text { común }\end{array}$ & $\begin{array}{l}\text { Los discentes responsables de la actividad expondrán } \\
\text { en clase sus investigaciones. Podrán emplear los medios } \\
\text { que consideren oportunos: presentaciones en ppt, vi- } \\
\text { sionado de fragmentos del filme, lecturas, etc. }\end{array}$ \\
\hline \multirow{2}{*}{ Debate } & $\begin{array}{l}\text { Arquitecturas y decorados efímeros: función y utilidad } \\
\text { La fiesta como práctica del poder y signo de ostentac- } \\
\text { ión } \\
\text { Decoraciones simbólicas como elementos de persua- } \\
\text { sión }\end{array}$ \\
\hline
\end{tabular}

\section{COMPENDIO DE PELÍCULAS SOBRE ARTE Y ARTISTAS DE LA EDAD MODERNA ${ }^{31}$}

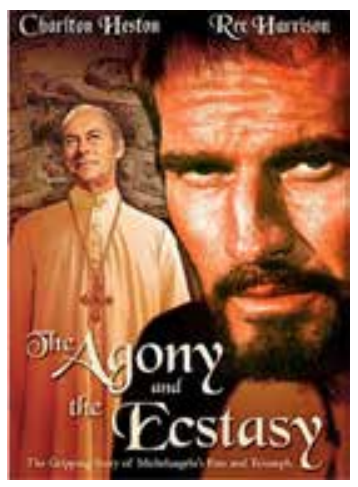

El tormento y el éxtasis (The Agony and the Ecstasy) ${ }^{32}$, basada en la vida de Miguel Ángel y dirigida por Carol Reed en el año $1965^{33}$. Basada en fragmentos de la novela de Irving Stone del mismo título, en esta película asistimos a la tumultuosa relación entre el Papa Julio II y Michelangelo Buonarrotti durante la realización de la Capilla Sixtina.

Una de las más conocidas obras de este artista, el Moisés (1515), una escultura que forma parte del mausoleo del papa Julio II, es la protagonista de Lo sguardo di Michelangelo (2004) $)^{34}$,

31 Para realizar este compendio hemos tomado como base el interesante trabajo web del profesor Enrique Martínez-Salanova Sánchez disponible en la url: <http://www.uhu.es/cine.educacion/ cineyeducacion/pintura_cine.htm> (Consultado: 20.02.2014).

32 El tormento y el éxtasis. Año: 1965. País: Estados Unidos. Duración: 136 minutos. Director: Carol Reed. Intérpretes: Charlton Heston, Rex Harrison, Diane Cilento, Harry Andrews, Alberto Lupo. <http://www.filmaffinity.com/es/film610438.html> (Consultado: 20.02.2014).

33 <http://cincecritic360.blogspot.com.es/2012/02/cine-clasico-el-tormento-y-el-extasis_06.html>; <http://www.centrocp.com/el-tormento-y-el-extasis/>; <http://www.artecreha.com/El_arte_en_ el_cine/el-tormento-y-el-extasis.html> (Consultado: 20.02.2014).

34 Lo sguardo di Michelangelo. Año: 2004. País: Italia. Duración: 17,34 minutos. Director: Michelangelo Antonioni. Intérprete: Michelangelo Antonioni. <http://www.youtube.com/watch?v=6A5bVWwu-qQ> (Consultado: 27/2/2014). Cfr.: Melendo, A., «De Michelangelo Buonarrotti en El Moisés, 1515, a Michelangelo Antonioni en Lo sguardo di Michelangelo, 2004", Revista Latente, no 6, 2009, pp. 121-131. 
corto dirigido por Michelangelo Antonioni ${ }^{35}$ en el que muestra su particular visión de esta popular imagen.
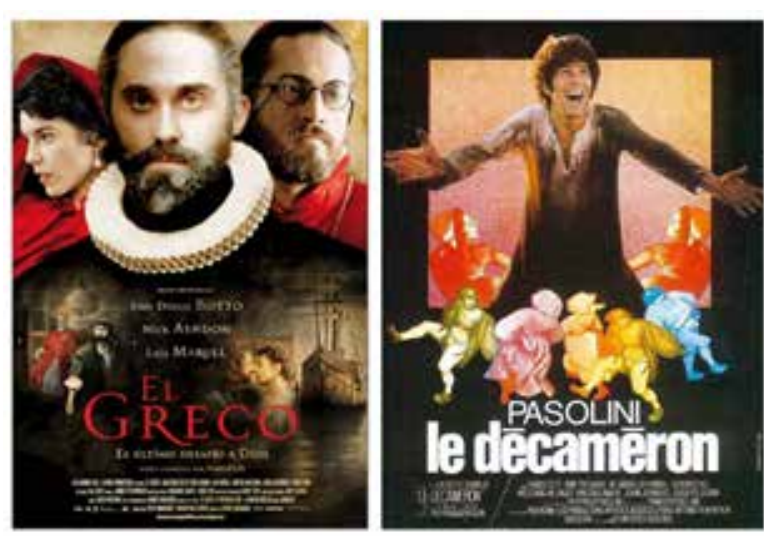

El Greco $^{36}$, primera producción sobre la vida del pintor cretense, dirigida por Luciano Salce en 1966. Es una película que narra la vida del artista, quien es detenido por la Inquisición y acusado de herejía, lo que conlleva drásticas consecuencias a su vida personal. En el año $2007^{37}$ fue estrenada una nueva producción sobre el pintor, dirigida por Iannis Smaragdis basada en la novela del escritor Dimitris Siatíopulos con el mismo título ${ }^{38}$.

El Decamerón (Il Decameron) ${ }^{39}$ fue una película dirigida por Pier Paolo Pasolini en $1971^{40}$. Una producción italiana con un gran reparto e inspirada en la obra de Boccaccio. En el filme pudimos ver a Passolini como pintor, interpretando a un discípulo de Giotto.

$35<$ http://glup2.blogspot.com.es/2011/02/lo-sguardo-di-michelangelo-michelangelo.html>; $<$ http://www.rouge.com.au/4/antonioni.html>; <http://arielluque.blogspot.com.es/2008/02/ lo-sguardo-de-michelangelo-antonioni.html> (Consultado: 20.02.2014).

36 El Greco. Año: 1966. País: España, Francia e Italia. Duración: 95 minutos. Director: Luciano Salce. Intérpretes: Rosanna Schiaffino, Mel Ferrer, Adolfo Celi, Mario Feliciani; El Greco, Año: 2007. País: España y Grecia. Duración: 117 minutos. Director: Iannis Smaragdis. Intérpretes: Nick Ashdon, Juan Diego Botto, Laia Marull, Vangelis, Jackie Pavlenko, Dimitris Siatopoulos. <http://www.filmaffinity.com/es/film865957.html> (Consultado: 27.02.2014).

$37<$ http://www.cinehistoria.com/el_greco.pdf> (Consultado: 20.02.2014).

38 El Greco. Año: 2007. País: Grecia. Duración: 119 minutos. Director: Yannis Smaragdis. Intérpretes: Nick Ashdon, Juan Diego Botto, Laia Marull, Lakis Lazopoulos, Roger Coma, Nick Ashdon, Dina Konsta. <http://www.filmaffinity.com/es/film971412.html> (Consultado: 27.02.2014). Cfr:: Mingo, A. y Martínez-Burgos, P., El Greco en el cine, Toledo, Ed. Celya y Sociedad de Eventos Culturales El Greco, 2014.

39 El Decamerón. Año: 1971. País: Italia. Duración: 111 minutos. Director: Pier Paolo Pasolini. Intérpretes; Franco Cinti, Pier Paolo Pasolini, Ninetto Davoli, Vincenzo Amato, Angela Luce, Silvana Mangano. <http://www.filmaffinity.com/es/film711651.html> (Consultado: 27.02.2014)

40 <http://cineultramundo.blogspot.com.es/2012/01/critica-de-el-decameron-por-ivan-suarez. html>; <http://quegrandeeselcinema.blogspot.com.es/2007/07/el-decamern.html> (Consultado: 27.02.2014). 
El contrato del dibujante (The Draughtsman's Contract) ${ }^{41}$ es un filme dirigido por Peter Greenaway ${ }^{42}$ en 1982 que muestra la vida de un dibujante del siglo xvir que quiere representar la verdad. La película es una reflexión sobre la perspectiva contada a través de una historia de intriga y pasiones entre la comitente y el artista.
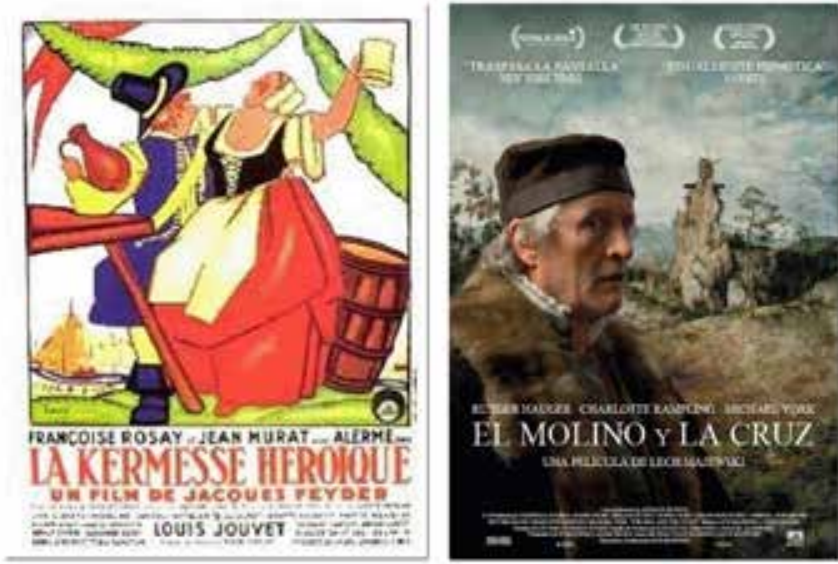

En el año 1935, una de las películas pioneras fue La Kermesse heroica (Carnival in Flanders $\left.{ }^{43}\right)$, de Jaques Feyder ${ }^{44}$, película de singular relevancia al rendir homenaje a la vinculación holandesa y española en el siglo XVII. Los soldados españoles llegan a un pueblo de Flandes y ante la preocupación de los lugareños, se celebra una gran fiesta. En el filme se puede ver la influencia de las obras de Pieter Brueghel el Viejo. Una de las pinturas de este artista holandés "Cristo cargando con la cruz» (1564) inspira una nueva película: $E l$ molino y la cruz (The Mill and the Cross, Lech Majewski, 2011) ${ }^{45}$ en la que se enlazan la vida de los personajes representados en el cuadro con la realización de la pintura ${ }^{46}$.

${ }^{41}$ El contrato del dibujante. Año: 1982. País: Gran Bretaña. Duración: 103 minutos. Director: Peter Greenaway. Intérpretes: Anthony Higgins, Janet Suzman, Anne Louise Lambert, Neil Cunningham, Hugh Frasier, David Grant, Dave Hill. <http://www.filmaffinity.com/es/film794361.html> (Consultado: 27.02.2014).

42 <http://www.laoffoffcritica.com/criticas/critica_contratodeldibujante.html>; <http://espiralcromatica.wordpress.com/2009/12/22/el-contrato-del-dibujante-de-peter-greenaway/>

43 La Kermesse heroica. Año: 1935. País: Francia. Duración: 115 min. Director: Jacques Feyder. Intérpretes: Françoise Rosay, Jean Murat, Louis Jouvet, Micheline Cheirel, Lyne Clévers, Alfred Adam. <http://www.filmaffinity.com/es/film685690.html> (Consultado: 27.02.2014).

44 <http://miradas.net/2009/08/estudios/la-kermesse-heroica.html>; <http://warblackwest. blogspot.com.es/2011/02/la-kermesse-heroica.html>; <http://www.elespectadorimaginario.com/la-kermesse-heroica/>; <http://www.auladecine.ulpgc.es/cine/auladecine/img/img_ pelis_03_11/1er-\%202006-2007/Maestros\%20Franceses\%20Olvidados/No139_NEW-La_Kermesse_Heroica.pdf> (Consultado: 27.02.2014).

45 El molino y la cruz. Año: 2011. País: Polonia. Duración: 92 minutos. Director: Lech Majewski. Intérpretes: Rutger Hauer, Charlotte Rampling, Michael York, Joanna Litwin, Dorota Lis, Bartosz Capowicz, Mateusz Machnik, Marian Makulan. <http://www.filmaffinity.com/es/film437758. html> (Consultado: 27.02.2014).

46 <http://www.locoporelcine.com/2012/12/critica-el-molino-y-la-cruz.html>;<http://cinedivergente.com/criticas/singularidades/el-molino-y-la-cruz>; <http:/www.criticscinema.com/criticas/ peliculas/El_molino_la_cruz.php> (Consultado: 27.02.2014). 

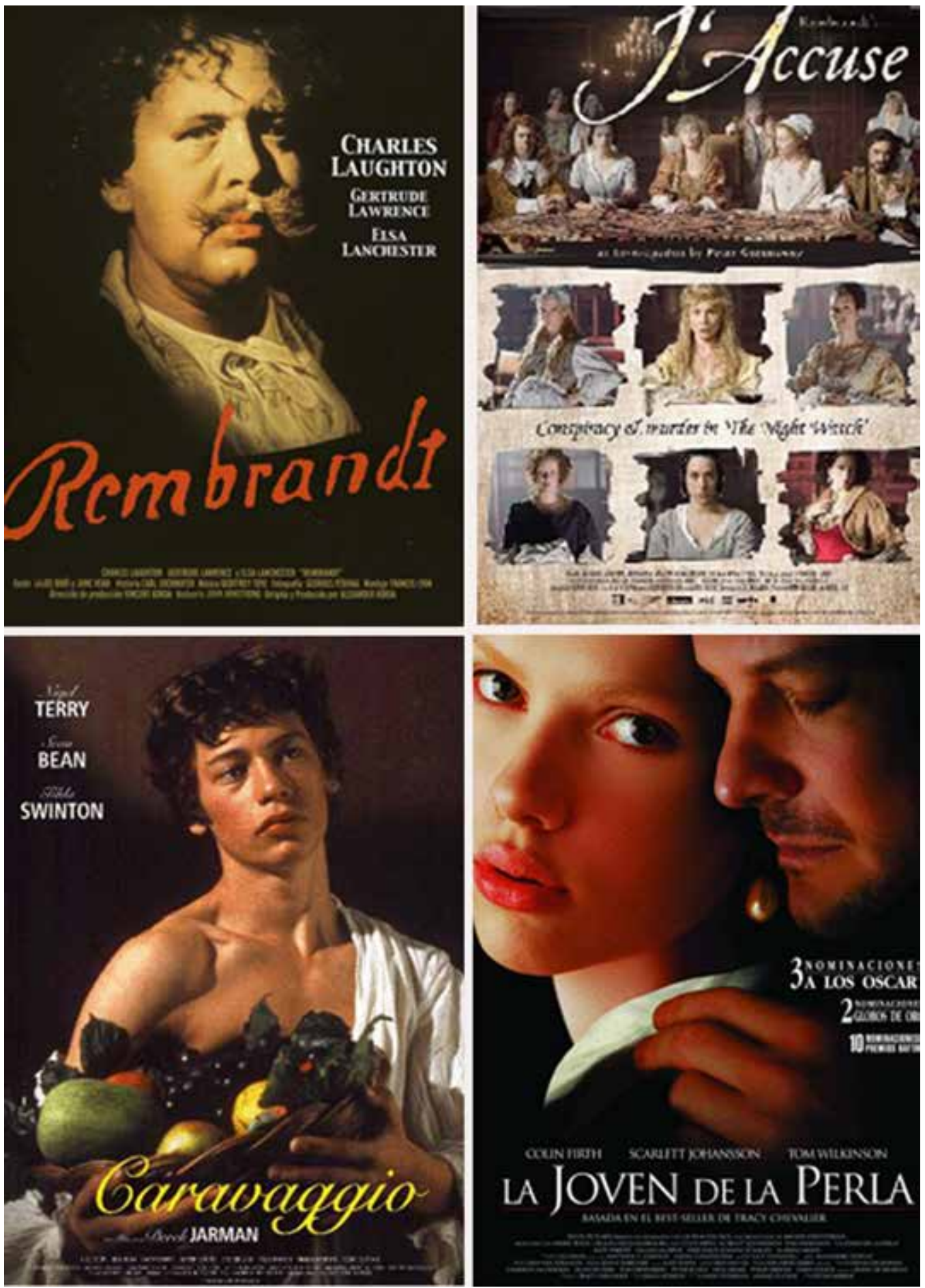
El primer filme sobre Rembrandt ${ }^{47}$ fue dirigido por Alexander Korda ${ }^{48}$ en 1936. Fue una de las primeras películas, junto a La kermese, en la que pudimos ver la inspiración de lo artístico como tema para un filme. En esta película de Korda se narra la vida del pintor tras la muerte de su esposa Saskia en el año 1642 y lo que supuso para su carrera profesional posterior. El filme es un interesante reflejo de la sociedad de su tiempo, de las distinciones sociales y los prejuicios que impidieron volver a contraer matrimonio con su nuevo amor.

La tormentosa vida del artista y su obra vuelven a ser las protagonistas de tres nuevas películas: Rembrandt fecit 1669 $9^{49}$ (1977), dirigida por Jos Stelling, Rembrandt $t^{50}$ (1999) cuyo director fue Charles Malton y en el año 2008 Peter Greenaway dirige Rembrandt's J'accuse!51 en el que especula sobre la trama que hay alrededor de uno de los cuadros más impactantes y conocidos del pintor, «La ronda de noche» (1640-1642). Es interesante la traslación de lo artístico al lenguaje plástico del cine, máxime cuando el visionado de todos estos filmes permite ver la evolución del lenguaje fílmico en sí y la estrecha relación entre la época y la pintura, convertida en imágenes de gran impacto visual.

En el año 1985, el director Derek Jarman ${ }^{52}$ llevó a la gran pantalla la vida de otro de los grandes pintores de la edad moderna, Caravaggio ${ }^{53}$, cuyo nombre es una

47 Rembrandt. Año: 1936. País: Gran Bretaña. Duración: 85 minutos. Director: Alexander Korda. Intérpretes: Charles Laugthon, Gertrude Lawrence, Elsa Manchester, Edward Chapman. <http:// www.filmaffinity.com/es/film848337.html> (Consultado: 27.02.2014). <http://39escalones.wordpress.com/2009/07/10/apoteosis-del-emporio-korda-rembrandt/>

49 Rembrandt fecit 1669. Año: 1977. País: Países Bajos. Duración: 120 minutos. Director: Jos Stelling. Intérpretes: Frans Stelling, Ton de Koff, Hanneke van der Velden, Lucie Singeling, Aya Gill, Ed Kolmeijer, Henk Douze. <http://www.filmaffinity.com/es/film244592.html> (Consultado: 27.02.2014).

50 Rembrandt. Año: 1999. País: Alemania, Francia, Holanda. Duración: 99 minutos. Director: Charles Matton. Intérpretes: Klaus Maria Brandauer, Romane Bohringer, Hendrickje Stoffels, Jean Rochefort, Nicolaes Tulp, Johanna ter Steege. <http://www.filmaffinity.com/es/film449399. html> (Consultado: 27.02.2014).

51 Rembrandt's J'accuse. Año: 2008. País: Holanda, Alemania, Finlandia. Duración: 86 minutos. Director: Peter Greenaway. Intérpretes: Martin Freeman, Eva Birthistle, Jodhi May, Emily Holmes, Jonathan Holmes, Michael Teigen, Natalie Press, Peter Greenaway. <http:/www.filmaffinity.com/ es/film212992.html> (Consultado: 27.02.2014).

52 Moriente, David, "la sensual aberración del anacronismo y el perfil bajo: Caravaggio de Derek Jarman» en <http://e-archivo.uc3m.es/bitstream/handle/10016/11371/sensual_moriente_CIHC_2010.pdf;jsessionid=C878C2F1D106671608CD06262EABB3C8? sequence=1 >; <http://www.artecreha.com/El_arte_en_el_cine/caravaggio.html> (Consultado: 27.02.2014). pretes: Nigel Terry, Sean Bean, Dexter Fletcher, Spencer Leigh, Tilda Swinton, Michael Gough. <http://www.filmaffinity.com/es/film757283.html> (Consultado: 27.02.2014). 
manifiesta recreación de la trayectoria del pintor Michelangelo Merisi. La narración se inicia con Caravaggio en el lecho de muerte, quien a partir del uso del flash back, hace un repaso biográfico de su vida como artista, las vicisitudes y las relaciones con el poder dominante. Algunos años después, en 2007, Angelo Longoni dirigió un nuevo filme ${ }^{54}$ en el que la vida de este incomprendido pintor vuelve a ser la protagonista.

Hace poco más de una década pudimos ver otra de las grandes versiones e interpretaciones de vidas de pintores, La joven de la perla (Girl with a Pearl Earring, Peter Webber, 2003) $)^{55}$ en una bella ambientación que muestra la obra del pintor Johannes Vermeer ${ }^{56}$, y al igual que otras películas que han antecedido el relato de las vidas de pintores, la trama amorosa se convierte en motivo de interés para el espectador.

Las pintoras, menos conocidas y consideradas en esta época, no han merecido apenas la atención de la filmografía actual; no obstante, desde hace unos ańos, un nombre despunta sobre las demás. Se trata de Artemisia, hija de Orazio Gentileschi, con el que aprendió su oficio. La película homónima de Agnès Merlet (Artemisia, 1997) ${ }^{57}$ presenta la complicada juventud de esta apasionada mujer que tuvo que enfrentarse a las normas morales establecidas.

\section{CONCLUSIONES}

Actualmente existen una gran cantidad de herramientas y entornos en la red que nos permite interaccionar e incluir ese material en el estudio específico de nuestras disciplinas, y por extensión en nuestras aulas, ya sea en el ámbito disciplinar de lo artístico u otras áreas. Este trabajo surgió con el objetivo de mostrar cómo se pueden utilizar las herramientas y recursos de la red para generar conocimiento. En las dos últimas décadas, los investigadores de la disciplina humanística de historia del arte han tenido que

54 Caravaggio. Año: 2007. País: Italia, España, Alemania. Duración: 180 minutos. Director: Angelo Longoni. Intérpretes: Alessio Boni, Claire Keim, Jordi Mollà, Paolo Briguglia, Benjamin Sadler, Elena Sofia Ricci, Sarhan Felberbaum. <http://www.filmaffinity.com/es/film682454.html>; (Consultado: 27.02.2014).

55 La joven de la perla. Año: 2003. País: Reino Unido. Duración: 95 min. Director: Peter Webber. Intérpretes: Colin Firth, Scarlett Johansson, Tom Wilkinson, Judy Parfitt, Cillian Murphy, Essie Davis, Joanna Scanlan. <http:/www.filmaffinity.com/es/film759947.html> (Consultado: 27.02.2014).

56 <http://www.universocinema.com/UC\%20CRITICAS/La_Joven_de_la_Perla.html>; <http:// www.laoffoffcritica.com/criticas/cr20040226.html> (Consultado: 27.02.2014).

57 Artemisia. Año: 1997. País: Francia, Alemania, Italia. Duración: 97 minutos. Directora: Agnès Merlet. Intérpretes: Valentina Cervi, Michel Serrault, Miki Manojlovic, Luca Zingaretti, Emmanuelle Devos, Frédéric Pierrot, Maurice Garrel, Brigitte Catillon. <http://www.filmaffinity. com/es/film845609.html>; <http://www.sensacine.com/peliculas/pelicula-10415/> (Consultado: 27.02.2014). 
actualizar sus metodologías y ampliar los objetos de estudio propios de la disciplina, extendiendo sus teorías a los productos y demás objetos fruto de los mass-media y la cultura visual. En el último siglo la imagen en movimiento fue una realidad, el cine surgió y se perfeccionó década a década convirtiéndose en el medio de entretenimiento más popular en todos los países industrializados. Sin embargo, la creación de la imagen fija, que durante siglos era producida casi en exclusiva por artistas y artesanos, se expande a otras áreas de creación, de ahí que se realicen hibridaciones entre metodologías de estudio y análisis de disciplinas humanísticas afines, históricas, artísticas, de comunicación visual, etc., además de trasposiciones de la imagen fija de lo artístico a la imagen en movimiento. Uno de los signos de nuestro tiempo es el consumo de la imagen, tanto fija como en movimiento, la realidad nos revela que nuestras generaciones, tanto investigadores, docentes como alumnos, hemos crecido rodeados de dispositivos tecnológicos y demás recursos digitales, éstos se han convertido en parte indispensables de nuestra vida cotidiana. Nuestro aprendizaje e investigaciones, quedan mediatizados por el consumo de la imagen, de ahí que gran parte de la información que nos llega de los aparatos digitales sea, bien como imagen fija o en movimiento. En esta tesitura, es donde defendemos la importancia del conocimiento del uso y «manipulación» de la imagen que realizan los medios audiovisuales.

Desde la introducción de este texto exponíamos las relaciones entre el arte y el cine, sobre todo, a lo largo de la segunda mitad del siglo xx, el cine se ha inspirado en la vida u obra de algunos grandes artistas o periodos históricos. Son numerosos los filmes de temática histórica. Esas recreaciones visuales nos muestran un escenario ficticio que suele estar inspirado, algunas veces con más o menos fortuna, en los textos e investigaciones de los especialistas. Por tanto, el cine además de tener ese poder persuasivo que lo caracteriza, irrumpe como una herramienta educativa de gran valor, puesto que puede emplearse para la ampliación y profundización del estudio de una época o autor determinado en distintos estadios de nuestro sistema educativo.

En los últimos años se está expandiendo su uso en la educación superior, de ahí que este estudio, tiene como objetivo fundamental proponer un ejemplo de intensificación de contenidos de una época histórica, como es la Edad Moderna, ofreciendo de forma concreta y específica, una actividad basada en el uso del filme como herramienta educativa de gran valor, en este sentido, el cinefórum cobra sentido, y es utilizado como complemento de un bloque teórico en una asignatura en particular, de modo que nos ayuda a visualizar la teoría, a leer la imagen y conocer los rasgos esenciales de un determinado estilo, a la vez que nos ayuda a identificar errores históricos o artísticos fruto del conocimiento y el aprendizaje del tema. Además de la propuesta, el trabajo ofrece una compilación de filmes del mismo periodo para que sirvan de base para la ampliación de contenidos. Su objetivo en este estudio específico, no es hacer un análisis fílmico exhaustivo del metraje compilado, sino ayudar a la puesta en práctica de este tipo de actividad 
proponiendo un repertorio de filmes para iniciar otros estudios que se complementan con metodologías de otras disciplinas.

En base a las observaciones expuestas, cabe reiterar que el lenguaje fílmico tiene sus particularidades, algo que es necesario para que el estudioso identifique entre lo real y lo imaginado, entre lo figurado y lo inventado, tal que el análisis de lo visualizado sirva para ampliar los contenidos específicos de un periodo histórico, adornarlo, registrar lo imaginado tras el estudio, y proceder al análisis y la reflexión teórica necesaria para el aprendizaje. Por tanto, la apropiación y uso de los recursos audiovisuales que nos ofrece nuestro tiempo debe considerarse, más una obligación que un entretenimiento, puesto que ayuda a complementar los múltiples modos de aprendizaje, enfoques, estudios y aproximaciones que se pueden realizar a un periodo en cuestión, y que a pesar de exceder los objetivos de este estudio, son necesarios para acceder a un aprendizaje completo sobre los temas a investigar.

\section{BIBLIOGRAFÍA}

AA. VV., «El cinema: fonts i recursos didactics». Graó. Barcelona, no 5, enero de 1996.

AA. VV., «Els audiovisuals a l'aula. El cinema a l'escola». Generalitat de Catalunya. Departament d'Ensenyament. $1^{\text {a }}$ edicio, abril de 1998.

AA.VV., Historia general del cine, Madrid, Cátedra, 1995, 12 vols.

Aguilar, C., Guía del cine español. Madrid, Cátedra, 2007.

BENET, V. J., Un siglo en sombras. Introducción a la historia y la estética del cine, Valencia, Ediciones de La Mirada, 1999.

Calero Ruiz, C., "Vatel y otros arquitectos de sueños efimeros. Banquetes, sentidos y triunfi en las cortes europeas de la época moderna». Revista Latente, no 9, 2011, pp. 45-58.

Calvo Serraller, F., «La fotogenia cinematográfica de los artistas», Arte y parte, $n^{\circ}$ 28, Madrid, Editorial Arte y Parte, 2000, pp. 82-94.

Camarero, G., Pintores en el cine, Madrid, Ediciones JC Clementine, 2009.

Carracedo Manzanera, C., "Diez ideas para aplicar el cine en el aula», en $I$ Congreso de Español como Lengua Extranjera en Asia-Pacífico, pp. 229-267. [<http://cvc.cervantes.es/ensenanza/biblioteca_ele/publicaciones_centros/ pdf/manila_2009/16_aplicaciones_03.pdf> (Consultado: 20/2/2014)]. 
Casetti, F., Teorías del cine, Madrid, Cátedra, 1994.

Fuentes Torres, M. Á. y Medina Galeote, J., «Modos y representaciones del artista en el cine. Fichas de películas de artistas y de Picasso y su obra» en Gómez Gómez, A. (Coord.), Cine, arte y artistas, Fundación Picasso y Ayuntamiento de Málaga, 2008, pp. 135-214.

García Gómez, F., «La docencia de la historia del cine desde el punto de vista de un historiador del arte», Revista Latente, no 6, 2008, pp. 67-72.

García OchOA, S., "Cine e iconología: análisis del film desde la historia del arte» en Quintana, no 4, 2005, pp. 153-163.

Gavilán Sánchez, J. A. y Lamarca Rosales, M., Conversaciones con cineastas españoles, Universidad de Córdoba, 2002.

Gómez Álvarez, J. L., «Fuentes iconográficas del imaginario histórico-artístico de los estudiantes de la enseñanza media espańola», Toleitola. Revista de educaión del CEP de Toledo, no 9, 2007, pp. 61-62 [<http://redined.mecd. gob.es/xmlui/bitstream/handle/11162/93638/00620093000020.pdf?sequence $=1>($ Consultado: 20/2/2014) .

Gómez Gómez, A. (coord.), Cine, arte y artistas, Fundación Picasso y Ayuntamiento de Málaga, 2008.

Gubern, R., Historia del cine, Barcelona, Lumen, 1995.

Herrera, J., «Dalí en el legado Buñuel», Revista Latente, n 5, 2007, pp. 143-154.

Hueso Montón, A. L., "Un director en continua progresión. La obra de Carlos Saura», Voir et lire Carlos Saura (III). ¡Ay, Carmela!, Dijon, Université de Bourgogne, 2000.

Hueso Montón, A. L., «La historia en el cine: cuestiones de método», Ficciones históricas. Cuadernos de la Academia, no 6, 1999, pp. 23-32.

Martel Lucini, J. C.: "Carlos Saura», LEER. El magazine literario, no 92, pp. 64-66, 1997.

Martínez Salanova, E., «Utilización del cine en las aulas. Aprender pasándolo de película», Revista Comunicar, no 11, 1998, pp. 27-36. 
Melendo, A., «De Michelangelo Buonarrotti en El Moisés, 1515, A Michelangelo Antonioni en Lo sguardo di Michelangelo, 2004», Revista Latente, no 6, 2009, pp. 121-131.

Mingo, A. y Martínez-Burgos, P., El Greco en el cine, Toledo, Ed. Celya y Sociedad de Eventos Culturales El Greco, 2014.

Órtiz Villeta, A., «La mujer pintora: Frida (Julie Taymor, 2002), en GómeZ Gómez, A. (coord.), Cine, arte y artistas, Fundación Picasso y Ayuntamiento de Málaga, 2008, pp. 123-134.

Otero VÁzquez, E., "Goya-Saura-Storaro: Tres artistas en el séptimo arte», Revista Latente, no 7, 2011, pp. 107-121.

Palacio, M., «La obra de Carlos Saura en la crítica especializada española», en Le cinéma de Carlos Saura, Bordeaux, Presses Universitaires, 1984.

PayÁn, M. J, El cine español actual, Madrid, Ediciones JC, 2001.

Poyato Sánchez, P., «Fulgor ígneo y escritura en El Loco del pelo rojo de Minelli (a propósito de la incorporación de la pintura de Van Gogh al texto fílmico)» en Gómez, A. (coord.), Cine, arte y artistas, Fundación Picasso y Ayuntamiento de Málaga, 2008, pp. 97-122.

Ramírez, J.A., Medios de masas e historia del arte, Madrid, Cátedra, 1988.

YePes, A. L., «Bibliografía española sobre Historia del cine», en Documentación de las ciencias de la información, vol. VI. Univ. Complutense. Madrid, 1982, pp. 41-55.

Valero Martínez, T., "Cine e Historia: una propuesta didáctica». Making Of, $n^{\circ} 32,2005$, pp. 21-26. 
Página intencionadamente en blanco 